\title{
Sex Differences in Histomorphology of the Human Carotid Body
}

\author{
Johnstone M Muthoka*, Jameela Hassanali Adel A Malek, Pamella Mandela and Julius A Ogeng'o \\ Department of Human Anatomy, University of Nairobi, Kenya
}

*Corresponding author: Johnstone M Muthoka, PO Box 30197,00100; Nairobi, Kenya, Tel: +254 724814 435; Email: muthokajm@gmail.com

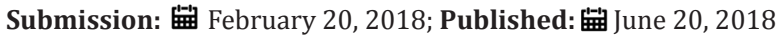

\begin{abstract}
Summary
Knowledge of sex differences in the histomorphology of the carotid body is important in understanding observed differences in respiratory function and disorders. There are few studies on sex differences in the carotid body. This study therefore aimed at describing these differences in the histomorphology features of the human carotid body. Thirty six random carotid bodies from cardiovascular disease free individuals ( 20 male, 16 female) obtained during autopsy at the Department of Human Anatomy, University of Nairobi were studied. Specimens obtained within 48 hours of death were fixed in 10\% formaldehyde solution and processed routinely for paraffin embedding. Seven micron thick serial sections were stained with H\&E, Mason's trichrome and examined with light microscope. Stereology was done to determine area occupied by parenchyma, stroma and vasculature. Data were analyzed using SPSS version 13.0. The student's $t$ test was used to compare sex differences. The data are represented using tables and macrographs.

The human carotid body is highly cellular with two varieties of cells namely; chief and sustentacular. It is heavily vascularised and densely innervated. Females showed higher concentration of chief cells, more profuse vascularization and denser innervation when compared with their aged matched male counterparts. The aging changes characterized by fibrosis, cellular degeneration vascular and neural attenuation are less severe in females. Sex histomorphological differences in the human carotid body characterized by higher population of chief cells, density of vascularity, innervation and blunted age related morphological attenuation underpin differences in its function and disease.
\end{abstract}

Keywords: Gender differences; Carotid body; Cells; Vascularization

\section{Introduction}

Knowledge of sex differences in the histomorphology of the human carotid body (HCB) is important in explaining the differences in respiratory function, responses and disease predisposition $[1,2]$. Functionally, there are sex differences in the ventilatory response to hypoxia (VRH) and hypercapnia [1,3-5], response in ventilatory control under acute or chronic hypoxic stimulation morphine induced ventilatory depression [6], ventilatory roll off and post hypoxia facilitation [7] and carotid body based control of ventilation [8]. Further, ovarian hormones affect CB function [9]. Regarding disease predisposition, hypoxia mediated ventilatory diseases like sudden infant death syndrome, mountain sickness, high attitude pulmonary edema and sleep apnoea occur more commonly in males and post-menopausal females [10-12]. There are also sex differences in symptoms, diagnosis and consequences of obstructive sleep apnoea [13]. There are, however, few studies on gender comparison of CB, with some denying variability [14]. This study therefore investigated the histomorphological features of CB in males and females with a view to defining any sex differences in this organ.
Materials and Methods

Table 1: Carotid body sample by age.

\begin{tabular}{|c|c|c|}
\hline Age-Set & Age-Group & Number \\
\hline \multirow{2}{*}{ Young } & \multirow{2}{*}{ (0-25yrs) } & M-5 \\
\hline & & F-5 \\
\hline \multirow{2}{*}{ Middle } & \multirow{2}{*}{ (26-59yrs) } & M-11 \\
\hline & & F- 6 \\
\hline \multirow{2}{*}{ Old } & \multirow{2}{*}{ (60yrs and above) } & $M-4$ \\
\hline & & $\mathrm{F}-5$ \\
\hline
\end{tabular}

Materials for this study comprised human carotid bodies obtained within 48 hours of death during autopsy at the Department of Human Anatomy, University of Nairobi. Ethical approval was obtained from the Kenyatta National Hospital Ethics Review Committee. Cases with history of cardiovascular disease such as hypertension, stroke, myocardial infarction, peripheral vascular disease and diabetes mellitus were excluded as were those with history of cardiovascular disease risk factors namely cigarette 
smoking obesity, hyperlipidemia and those who showed features of carotid atherosclerosis. Thirty six CB specimen, categorized under sex and age-sets as shown in Table 1 were studied. Whole carotid bodies, as well as carotid bifurcation were fixed in $10 \%$ formaldehyde for 12 hours and dehydrated in increasing alcohol series of 70\%, 80\%, 90\%, 95\% and 100\% ethanol for an hour in each grade. They were cleared using toluene and infiltrated in molten wax for 12 hours. Each carotid body was embedded in paraffin wax and oriented to its largest diameter, parallel to the plane of section. Seven micron thick serial sections were made using a sledge microtome. Five representative sections, selected from upper, middle and lower portions of the carotid body, were stained with Hematoxylin/Eosin and Mason's trichrome to demonstrate cells, nerves, connective and vascular tissue. The slides were examined Results using a light microscope at magnifications of X 40, X100 and X 400 . Representative micrographs of sections within the age groups were taken using a high resolution digital camera.

For stereological study, sections from the proximal, middle and distal parts of each carotid body, according to sex and age group were used. A magnified image (X 1000) of each slide was projected from the microscope onto a television screen and a transparency with a point counting grid $\left(2 \mathrm{~cm}^{2}\right)$ placed on it. The area occupied by parenchyma, stroma and vasculature was determined and percentages obtained recorded. Data was analyzed using SPSS 13.0. The student's t test was used to compare gender based differences in mean areas. The results are presented in macrographs and a table.

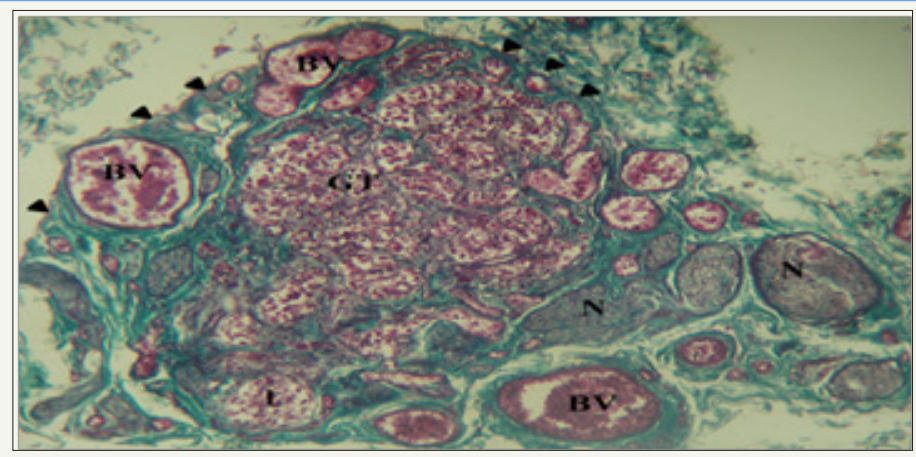

Figure 1: Photomicrograph of a section of the carotid body and surrounding structures.

The HCB was a highly cellular, richly vascularized and densely innervated organ. It was surrounded by a connective tissue capsule with septae that lobulated the organ. These septa contained glomic arterioles and nerve bundles (Figure 1).

The cellular glomic tissue (GT) is lobulated (1) and surrounded by a connective tissue capsule (arrowheads). It is abundantly supplied by nerve bundles ( $\mathrm{N}$ ) and blood vessels (BV). Mason's trichrome stain $\mathrm{x} 100$. Within lobes of the HCB, cells were arranged in clusters with a variable number of type I glomic cells (Chief cells) surrounded by type II sustentacular cells (Figure 2A \& 2B).
Type I cells had a rounded contour and contained a large eccentric nucleus. They appeared as dark, light or progenitor subtypes and had numerous cytoplasmic extensions. The staining characteristic of chief cell nuclei designates them as either dark or light varieties. They were both euchromatic with little cytoplasm and exhibit features of protein synthesizing cells. Progenitor cells had small heterochromatic nuclei, little cytoplasm and were scattered within each cluster. Sustentacular cells were spindle-shaped with faintly eosinophilic cytoplasm and elongated nuclei which were broader than the tapered nuclei of fibrocytes or crescentic nuclei of capillary endothelial cells.

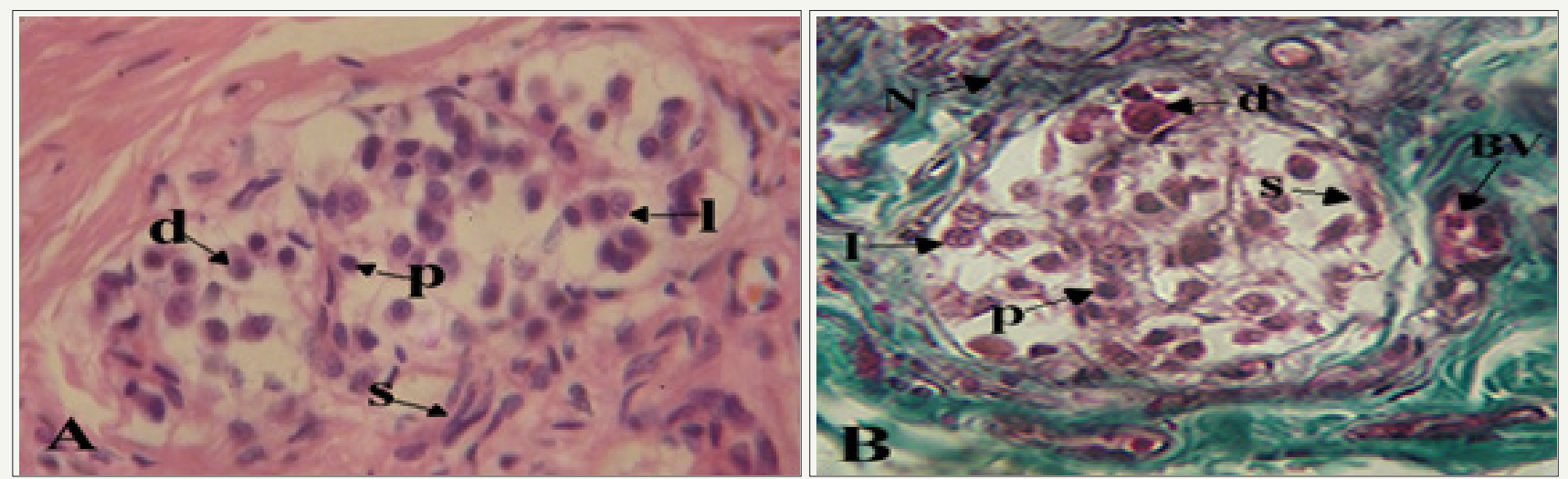

Figure 2: Photomicrographs showing clusters of cells in the carotid body.

A. s: Spindle-shaped sustentacular cells surround groups of chief cells; d: Dark; I: Light; p; Progenitor varieties. H\&E X400

B. BV: Note the proximity of blood vessel; N: Nerve to a cluster of cells. Mason's Trichrome X400 


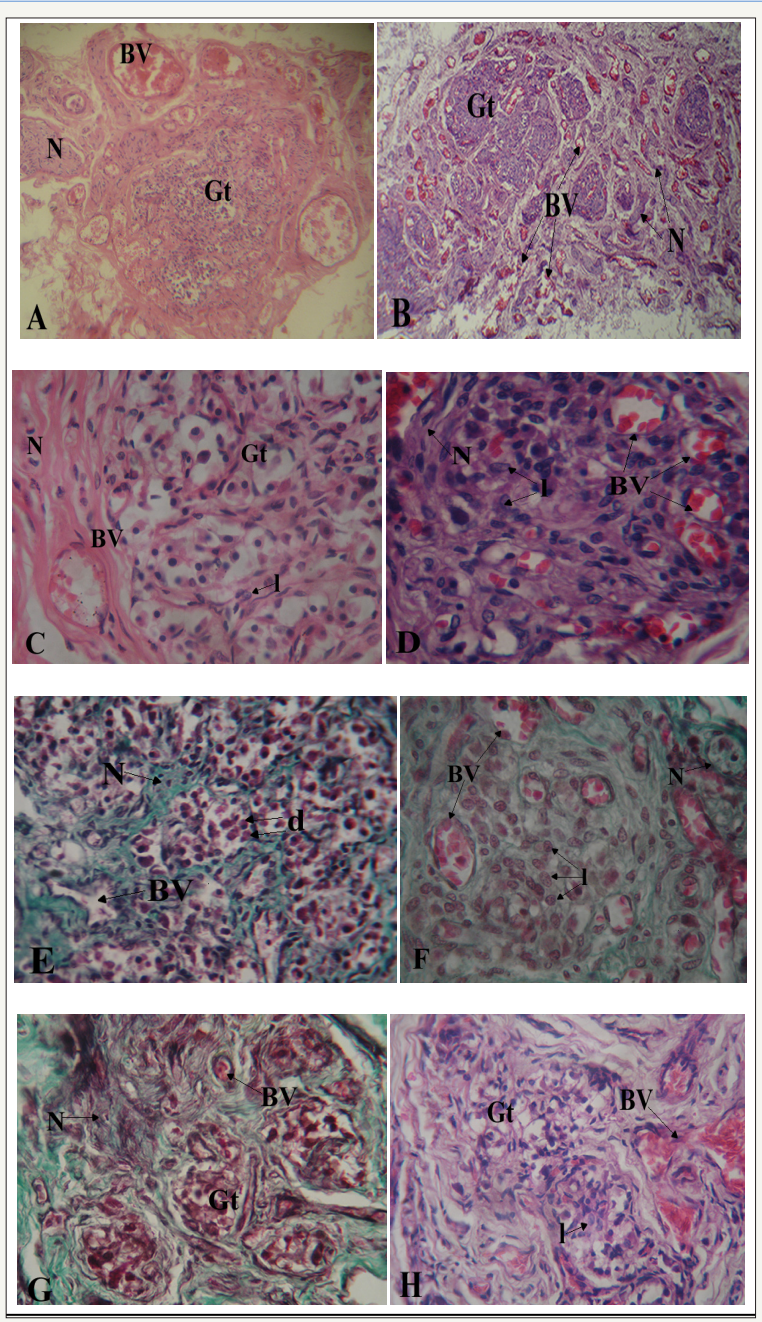

Figure 3 A-H: Photomicrographs showing sections of carotid bodies of males and females from different age groups. (A-D, H/E; E, F, G: Masson's Trichome x 400)

A. $\quad 2 y r$ old male. Blood vessels (BV) and nerves (N) are located around glomic tissue (Gt). X100

B. $\quad 3 y r$ old female specimen, note blood vessels (BV) and nerves (N) within the glomic tissue (Gt). X100.

C. $\quad 17 \mathrm{yr}$ old male. Note blood vessel (BV) and nerve (N) located in a septum at the periphery of glomic tissue (Gt). There are few light staining chief cells (1). X400

D. 22yr old female, note blood vessels (BV) and nerve (N) closely located amid clusters of light staining chief cells (l) with few dark (d) and progenitor (p) chief cells. X400

E. $\quad 42 y r$ old male showing blood vessel (BV) and nerve (N) located in connective tissue septa (s). Cell clusters are mainly composed of dark (d) chief cells. X400

F. $\quad 40 y r$ old female. Note the great number of light staining chief cells (1), blood vessels (BV) and nerves (N) located within glomic tissue (Gt).X400

G. $\quad 75 y$ old male. Lobules are degenerated and fibrosed. Blood vessels and nerves are few and scanty. X400

H. $\quad 82 y r$ old female. Fibrotic changes are similar to those seen in the male but with presence of few light cells (1). Blood supply is however well maintained (BV). X400

There were sex differences in the organization of glomic and neurovascular tissues. In the male, glomic tissue was compact and surrounded by large blood vessels and nerves with little ramification in septa (Figure $3 \mathrm{~A}$ ). In the female, glomic tissue was diffuse in scattered lobules that were intensely supplied by numerous blood vessels and nerves (Figure 3B). Within the lobes, capillaries and nerve branches were limited to septa with minimal parenchymal supply in males (Figure 3C-G). In the females, on the other hand, there was extensive supply to the cells within clusters with numerous capillaries being seen in the parenchyma (Figure
3D-H). In the cellular clusters, the populations of dark and light staining chief cells were similar in the male specimens studied and only the progenitor cells seemed to decline with age (Figure 3C \& 3E). In the females, however, there was a prominence of light staining chief cells with much fewer dark and progenitor varieties (Figure 3D \& 3F). Within the elderly, degenerative changes in glomic tissue showed the same pattern for both males and females with attendant connective tissue infiltration. Vascularization was, however, better preserved in the females (Figure 3G \& 3H). The average area of the HCB was determined for both sexes in the 
three age groups. It was slightly higher in the females for each age group and increased with age. The percentage of glomic tissue was higher in females for all age groups as was that of vascular tissue.
Connective tissue content was however higher in male specimens for all age groups (Table 2).

Table 2: Average area and percentages tissues found in the carotid body for different age groups in males and females.

\begin{tabular}{|c|c|c|c|c|c|c|c|c|}
\hline \multirow{3}{*}{ Age group } & \multirow{3}{*}{$\begin{array}{c}\text { Average Area }\left(\mathrm{cm}^{2}\right) \\
\text { Male }\end{array}$} & & \multicolumn{6}{|c|}{ Average Percentage of Tissues (\%) } \\
\hline & & \multicolumn{2}{|c|}{ Glomic } & \multicolumn{2}{|c|}{ Vascular } & \multicolumn{2}{|c|}{ Connective } & \multirow[b]{2}{*}{ Female } \\
\hline & & Female & Male & Female & Male & Female & Male & \\
\hline $0-25 y r$ & $0.36 \pm 0.05$ & $0.37 \pm 0.05$ & 70.2 & 75.7 & 8.2 & 12.3 & 21.6 & 12 \\
\hline $26-59 y r$ & $1.13 \pm 0.08$ & $1.15 \pm 0.07$ & 58.3 & 64.5 & 10.4 & 14.7 & 31.3 & 20.8 \\
\hline $60 y r+$ & $1.79 \pm 0.08$ & $1.84 \pm 0.08$ & 25.2 & 30.6 & 14 & 21.2 & 60.8 & 48.2 \\
\hline
\end{tabular}

Using the student's-t test the differences in mean area of the HCB between males and females was not statistically significant (twotailed $P$ value $=0.7969$ ).

\section{Discussion}

The parenchyma of the carotid body was composed of clusters comprising chief and sustentacular cells. It was richly vascularized and innervated. This basic structure is similar to that previously reported in domestic fowl [15], human [16], rabbit [17] and rat [2]. This suggests that cyto architecture of the CB is preserved across species, probably due to its role as the main arterial chemoreceptor in higher vertebrates [16]. The current study recorded major gender differences in vascularization, cellular density and age related attenuation in the CB. Females had more dense vascularization and innervation than males. This is at variance with reports that there are no structural differences between male and female HCB [14]. The high vascularity of HCB is essential to its function for detecting changes in the composition of blood [18-20].

Blood capillaries and sinusoids accompanied by nerve radicals within the cellular lobules ensure maximal contact of the cells with blood and nerve endings. The higher vascularity and innervation of the $\mathrm{CB}$ in females may constitute the structural basis for the higher functional capacity of the female especially in ventilatory roll off and post hypoxia facilitation [7], morphine induced ventilatory depression [6] and higher ventilatory response to hypoxia $[3,4]$. Pertinent to this is the suggestion that intra organ hemodynamica play a role in the process of chemoreception [2]. Studies on the VRH in mice and human subjects show an enhanced response in females when compared to their male counterparts [1,3]. Through ovariectomy in mice Mortola et al. [3] eliminated gonadal hormones as a determinant of the observed differences.

Females had a higher number of chief cells compared to their male counterparts in all age groups. These cells were light staining with a euchromatic nucleus reminiscent of highly active protein synthesizing cells. The chief cells are responsible for chemoreception and chemoresponse [21]. These cells produce a widerange of neurotransmitters including dopamine, noradrenaline and substance $P$ [22]. Accordingly, the higher number and evidence of activity may be responsible for the heightened activity of HCB in females. Pertinent to this suggestion are observations that chemoreceptor hypofunction leads to decreased peripheral drive for ventilation [23]. The transmitters released by the chief cells trigger a receptor potential and hence action potential on the adjoining afferent nerve [22]. Indeed reduction in neuronal like cells causes loss of sensory capabilities in transmission of chemoreceptor signals [24].

In both males and females, aging was associated with reduction in cellular, vascular and innervation density and increase in stroma. This was consistent with other reports $[14,23]$. In females, however, the attenuation was less severe in the sense that cellular and vascular density was comparatively better preserved. This is consistent with preservation of CB function which occurs in aged females [25-28]. The preservation of function albeit with fewer cells is probably related to the suggestion that only a small number of type I cells in the CB is sufficient to sustain functional activity [25,29-31].

\section{Conclusion}

Sex histomorphological differences in the human carotid body characterized by higher population of chief cells, density of vascularity, innervation and blunted age related morphological attenuation in females may underpin differences in respiratory function and disease predisposition.

\section{Acknowledgement}

We are grateful to Margaret Irungu, Judy Machira, Jacob Gimongo, Acleus Murunga for technical support and Antonina Odock- Opiko for typing and editing the manuscript.

\section{References}

1. De Mesones AR, Costas TP, Carasco GV, Tort CL, Farre JLV (2008) Sexlinked differences in Pulse Oxymetry. Br J Sports Med 42: 620-621.

2. Atanasova DY, Illiev ME, Lazarov NE (2011) Morphology of the rat carotid body. Biomed Rev 22: 41-55.

3. Mortola JP, Chikako S (1996) Ventilatory Response to hypoxia in rats: Gender difference. Respir Physiol 106(1): 21-34.

4. Holley HS, Behan M, Wenninger J (2011) Age and gender sex differences in the ventillatory response to hypoxia and hypercapria in awake neonatal, prepubertal and young adult rats. Resp Physiol Neurobiol 180(1): 79-87.

5. Goldberg S, Ollila HM, Lin L, Sharifi H, Rico T, et al. (2017) Analysis of hypoxic and hypercapric ventillatory in Healthy volunteers. PLOS ONE 12(1): e0168930. 
6. Sarton E, Teppema L, Dahan A (1999) Sex differences in morphineinduced ventillatory depression reside within the peripheral chemorefles loop. Anaesthesiology 90(5): 1329-1338.

7. Palmer LA, May WJ, deRonde K, Brown-Steinke K, Gaston B, et al. (2013) Hypoxia induced ventillatory roll-off and facilitation. Respir Physiol Neurobiol 185(3): 497-505.

8. Soliz J, Soulage C, Borter E, van Patot MT, Gassmann M (2008) Ventillatory responses to acute and chronic hypoxia are altered in female but not male Paskin-deficient mice. Am J Physiol Integr Comp Physiol 295(2): R649-R658.

9. Joseph V, Soliz J, Soria R, Pequignot J, Favier R, et al. (2002) Doperminergic metabolism in carotid bodies and high attitude acclimatization in female rats. AMJ Physiol Reg Integ Camp Physiol 282(3): R765-R773.

10. León-Velarde F, Ramos MA, Hernández JA, De Idiáquez D, Muñoz LS, et al. (1997) The role of menopause in the development of chronic mountain sickness. Am J Physiol 272(1): R90-R94.

11. Joseph V, Soliz J, Peguignot J, Sempore B, Cottet Emard JM, et al. (2000) Gender differenciation of the chemoreflex during growth at high altitude: functional and neurochemical studies. Am J Physiol Regul Integr Comp Physiol 278(4): R806-R816.

12. Basnyat B, Murdoch DR (2003) High altitude illness. Lancet 361(9373): 1967-1974.

13. Wimms A, Woehrle H, Ketheeswaran S, Rammanan D, Amitstead J (2016) Obstructive sleep apnea in women specific issues and interventions. Biomed Res Int 2016: 1764837.

14. Sarrat-Torres MA, Torres A, Whyte J, Baena S, Cisneros A, et al. (2006) Structure, location, function and pathological features of the human carotid body. Eur J Anat 10(1): 1-5.

15. Kameda Y (1994) Electron microscopic study on the development of the carotid body and glomus cell groups distributed in the wall of the common carotid artery and its branches in the chicken. J Comp Neurol 348(4): 544-555.

16. Fitzgerald RS, Machiko S, Alexander B, Courtney EG (2007) Oxygen sensing in the carotid body and its relation to heart failure. Antioxid Redox Signal 9(6): 745-749.

17. Eken E, Besoluk K, Hasan HD, Murat B (2008) A morphological study on the Carotid body of the Angora rabbit. Int J Exp Clin Anat 2: 49-54.

18. O’Reagan RG, Majcherczky S (1982) Role of peripheral chemoreceptors and central chemosensitivity in regulation of respiration and circulation. J Exp Biol 100: 23-40.
19. Barnett S, Mullligan E, Wagerle LC, Lahiri S (1988) Measurement of carotid body flow in cats by use of radioactive microspheres. J Appl Physiol 65: 2484-2489.

20.Zapata P, Larrain C (2005) How the carotid body works. Different strategies and preparations to solve different problems. Biol Res 38: 315-328.

21. Kumar P, Prabhakar NR (2012) Peripheral chemoreceptors: Function and plasticity of the carotid body. Comp Physiol 21(1): 141-219.

22. Fitzgerald RS, Eyzaguirre C, Zapata P (2009) Fifty years of progress in carotid body physiology-invited article. Adv Exp Med Biol 648: 19-28.

23. Conde SV, Obeso A, Rigual R, Monteiro EC, Gonzalez C (2006) Function of the rat carotid body chemoreceptors in ageing. J Neurochem 99(3): 711-723.

24. Mazzatenta A, Marconi GD, Zara S, Cataldi A, Porzionato A (2014) In the carotid body, galanin is a signal for neurogenesis in young and for neurodegenaration in the old and in drug addicted subjects. Front Physiol 5: 427.

25. Pokorski M, Walski M, Dymecka A, Marczak M (2004) The aging carotid body. J Physiol Pharmacol 55(3): 107-113.

26. Wenninger JM, Olson EB, Cotter CJ, Thomas CF, Behan M (2009) Hypoxic and hypercapnic ventillatory responses in aging male vs. aging female rats. J appl Physiol 106(5?): 1522-1526.

27. Lhuissier FJ, Canoui-Potrine F, Richalet JP (2012) Aging and cardiorespiratory response to hypoxia. J Physiol 590: 5461-5574.

28. Richalet JP, Ljuissier FJ (2015) Aging, tolerance to high attitude and cardio respiratory response to hypoxia. High Alt Med Biol 16(2): 1-8.

29. Pokorski M, Antosiewicz J (2010) Alterations in the hypoxic ventillatory response with advancing age in awake rats. J Physiol Pharmacol 61(2): 227-232.

30. Kline DD, Peng YJ, Manalo DJ, Semenza GL, Prabhakar NR (2002) Defective carotid body function and impaired ventilatory responses to chronic hypoxia in mice partially deficient for hypoxia-inducible factor 1a. Proc Natl Acad Sci USA 99(2): 821-826.

31. K, Pickett CK, Jacoby CR, Weil JV, Moore LG (1997) Role of endogeneous female hormones in hypoxic chemosensitivity. J Appl Physiol 83(5): 1706-1710.
Creative Commons Attribution 4.0 International License

For possible submissions Click Here

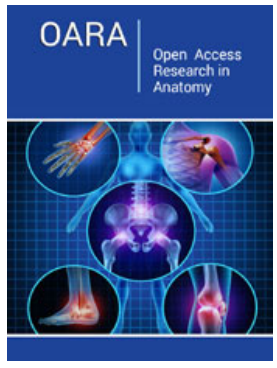

\section{Open Access Research in Anatomy}

\section{Benefits of Publishing with us}

- High-level peer review and editorial services

- Freely accessible online immediately upon publication

- Authors retain the copyright to their work

- Licensing it under a Creative Commons license

- Visibility through different online platforms 